\title{
PRACTICAL ASPECTS OF SOCIO-PSYCHOLOGICAL INFLUENCE IN THE FIELD OF HEALTHCARE IN UKRAINE
}

\section{Chovpan G. O., Batyuk L. V.}

\section{INTRODUCTION}

Ukraine recognizes as a priority democratic values, the formation of civil society and the rule of law, which determines the provision of public administration of effective tools of influence in individual and group interaction as a whole in the national economy and in its individual segments. Given the specifics of the domestic health care sector, public management of its development is carried out through the use of various methods of public administration. Since this area is in a state of permanent crisis, a radical improvement of the situation is possible only if it is carefully reformed, which is ensured by improving public administration, among which the leading place belongs to socio-psychological methods of influence.

The purpose and objectives of the study: to study the socio-psychological methods of public administration in the field of health care;

The object of study is the development of domestic health care.

The subject of research there are socio-psychological methods of public administration in the field of health care in Ukraine.

Research methods. abstract-logical - for theoretical generalizations and formation of conclusions; analysis and synthesis - to assess the parameters of health care development; statistical comparisons - to study the effectiveness of the application of socio-psychological influence in the field of health care.

The practical significance of the research results is to deepen existing ideas about the application of socio-psychological influence in the field of health care.

\section{Code of Ethics of Physicians of Ukraine as a means of social and psychological influence of public administration in the field of health care}

Human life and health are the main, fundamental values. The doctor's activities are aimed at preserving them from the moment of conception and require him to treat the person humanely, respect his personality, compassion and complicity, benevolence, charity and mercy, patience, mutual trust, decency and justice. The doctor must remember that the chief 
judge in his professional path is, first of all, conscience. These moral principles are systematized in the Code of Ethics of Physicians of Ukraine (hereinafter - the Code) taking into account the provisions of the International Code of Medical Ethics, the Declaration of Helsinki, the Universal Declaration on Genome and Human Rights and the Convention for the Protection of Human Rights and Dignity.

This Code is intended for use in the professional activities of physicians and scientists whose professional activities cover prenatal and postnatal life and human health, birth and death ${ }^{1}$.

The provisions of the Code must be complied with by doctors, administrative staff and scientists directly related to treatment and prevention and scientific activities in the field of health care, as well as nurses, students and interns of higher medical and postgraduate education institutions who assist doctors or replace them in the workplace ${ }^{2}$.

Ethical commissions and committees at health care institutions and scientific institutions should support and monitor the implementation of the Code; medical and scientific federations, associations, societies and other public organizations in the field of health care that recognize this Code.

Recognition of the Code by the medical staff of a health care institution, scientific institution, higher medical educational institution or postgraduate institution, medical or scientific federation, association, society or other public organization operating in the field of health care is confirmed by an official statement to the Commission. on Bioethics at the Ministry of Health of Ukraine (hereinafter - the Commission on Bioethics).

In case of violation of the Code by doctors of medical, scientific, educational institutions, members of federations, associations, societies or other public organizations operating in the field of health care and recognizing this Code, they may be subject to sanctions by ethics commissions or committees of these institutions. and organizations. The extreme form of public condemnation of the violation of professional and universal moral and ethical principles is the exclusion of a doctor or scientist from the professional association of which he is a member. In each case of non-recognition or violation of the Code by public organizations, individual legal entities and individuals operating in the field of health care, the relevant Bioethics Commission is obliged to investigate the possible negative consequences for individuals and society and to take measures for their prevention and elimination by applying to the relevant organizations

${ }^{1}$ Code of Ethics of the Doctor of Ukraine. Transport medicine of Ukraine. 2009. № 4. S. 6-11.

2 Doctor's code of ethics. URL: https://zl.com.ua/ua/etic\%20codex/ (access date: 01.10.2020). 
and public authorities for disciplinary, administrative and legal sanctions. In the event of unforeseen situations, unresolved issues and disputes regarding the interpretation, implementation or violation of the provisions of the Code, the final decision remains with the Bioethics Commission ${ }^{3}$.

The main purpose of the professional activity of a doctor (practitioner and scientist) is to preserve and protect human life and health in the prenatal and postnatal period, disease prevention and recovery, as well as reducing suffering from incurable diseases, at birth and death. Ethical treatment of the patient's personality does not cease after his death. The doctor performs his duties with respect for the life, dignity and autonomy of each person on the basis of moral and ethical principles of society, his own moral position and conscience, guided by the Oath of the Doctor of Ukraine and this Code.

The doctor is fully responsible for their decisions and actions regarding the lives and health of patients. $\mathrm{He}$ is obliged to systematically improve professionally, using in his activity the most effective of the previously known and latest achievements of medical science in the manner prescribed by law. ${ }^{4}$

The humane goals served by the doctor give him grounds to demand the legal protection of his moral and ethical positions and principles, personal dignity, the necessary material support, the creation of conditions for the implementation of professional activities. In no case can a doctor deprive himself of professional independence. Motives of material and personal gain, career, satisfaction of one's own ambitions should not prevail when a doctor makes professional decisions. In state treatment and prevention institutions, the doctor provides care to patients free of charge within the funding allocated to this institution. Demanding by the doctor from the patient or his relatives any remuneration not provided by laws and regulations is criminal and immoral. The doctor's right to private practice is regulated by law.

Medical associations are obliged to promote and assist each of their members in adhering to and upholding the principles of high professionalism, professional independence, morality, ethics and deontology.

The doctor has the right: for material remuneration of his work in the manner prescribed by law, to participate in the forms of protest provided by the legislation of Ukraine, but is not released from the obligation to provide the necessary medical care to patients who are under his supervision.

The doctor must: provide medical care to patients regardless of age, sex, race, nationality, religion; social status, political views, citizenship and other

3 Doctor's code of ethics. URL: https://zl.com.ua/ua/etic\%20codex/ (access date: 01.10.2020).

${ }^{4}$ Health systems, health and well-being: an assessment of the arguments in favor of investing in health systems. WHO, 2008. S. 125-132. 
non-medical factors; faithfully comply with the obligations, ethical norms and rules regarding the institution and staff in which he works or has worked before; to take an active part in the work of professional associations, while relying on their protection and support; by personal example and other means available to him (lectures, conversations, mass media, Internet, etc.) to promote a healthy way of life and to be an example in observance of its norms and rules; be honest with patients and colleagues, must fight the professional shortcomings of other doctors, must debunk deception and fraud; be a worthy example for your students and other members of society; must protect his right to a fair appraisal and remuneration of his work by the state, to avoid humiliation and financial discrimination when working in private institutions and during private practice; engage in any other activity if it is compatible with professional independence, does not degrade his dignity and does not harm patients and his medical practice. ${ }^{5}$

The doctor should not: engage in unfair advertising and allow the use of your name and expression to advertise inaccurate medical information; distribute for the purpose of profit medicines and medical devices, except for certain circumstances specified by law; to take part in collusion with doctors, pharmacists, representatives of the medical industry and other individuals or legal entities in order to obtain illegal income; accept remuneration from manufacturers and distributors for the appointment of their proposed drugs, medical, diagnostic and hygienic medical devices, dietary foods, except in certain circumstances specified by law; engage in other activities incompatible with his professional honor and authority; use your own elective, administrative or other official position to increase its own clientele; create conditions for illegal remuneration and tax evasion.

From the moment a doctor decides to personally provide any person with the necessary professional assistance or to involve him or her in research as a volunteer, he or she must base his or her actions on and relationship with that person on the principles of universal ethics and morality proclaimed. "Oath of the Doctor of Ukraine", medical deontology, as well as "Code of Ethics of the Doctor of Ukraine".

The doctor is responsible for the quality and humanity of the medical care provided to patients and any other professional actions related to the intervention in human life and health. In his work he is obliged to be guided by the Constitution and laws of Ukraine, current regulations for medical practice (medical standards), but within these provisions, given the nature of the disease, choose those methods of prevention, diagnosis and treatment that he considers most effective in in each case, guided by the interests of the

\footnotetext{
${ }^{5}$ Health systems, health and well-being: an assessment of the arguments in favor of investing in health systems. WHO, 2008. S. 125-132.
} 
patient. If necessary, the doctor must use the help of his colleagues. In situations of providing care to the patient, not provided by law, regulations and professional instructions, the doctor must be guided primarily by the interests of the patient, the principles of professional ethics and morality, to follow their own conscience. ${ }^{6}$

The doctor's actions should be aimed at achieving the maximum benefit for the life and health of the patient, his maximum social protection. Throughout the treatment, when providing information to the patient about his condition and the recommended treatment, the doctor must take into account the personal characteristics of the patient and monitor whether the patient correctly assesses the situation. The doctor should not interfere in the private affairs of the patient and his family members without sufficient professional reasons. The doctor should not expose the patient to undue risk, much less use his knowledge for inhumane purposes. When choosing any method of treatment, the doctor must first be guided by the principle of "Do no harm"! The doctor is obliged to give the patient as much time and attention as necessary to establish an accurate diagnosis, perform a full range of care, substantiation of prescriptions and recommendations for further treatment, providing them to the patient in a detailed and understandable to him. The doctor has no right to deliberately exaggerate or underestimate the severity of the disease in order to provide the patient with social protection and financial support that do not correspond to the real state of his health. Except in cases of emergency care, the doctor has the right to refuse treatment of the patient when he is sure that there is no necessary mutual trust between him and the patient, when he feels insufficiently competent or does not have the necessary treatment options and in other cases does not contradict the Oath of the Doctor of Ukraine. In this situation, the doctor should take all measures to inform the patient and give him appropriate recommendations.

The doctor must respect the patient's right to choose a doctor and participate in decisions on treatment and prevention measures, except in cases of involuntary treatment in the manner prescribed by law. The patient's free consent to examination, treatment or research with his participation is obtained by the doctor in a personal conversation with him. This consent must be informed, the patient must be informed about the methods of treatment, the consequences of their use, including possible complications, and other alternative treatments. If the patient is unable to consciously give his consent, it must be given by a legal representative or a person who constantly takes care of the patient. Carrying out medical and

\footnotetext{
${ }^{6}$ Health systems, health and well-being: an assessment of the arguments in favor of investing in health systems. WHO, 2008. S. 125-132.
} 
diagnostic measures without the patient's consent is allowed only in cases of threat to the life and health of the patient if he is unable to adequately assess the situation. Decisions in such cases must be made collectively and with the participation of his relatives. The doctor must take care of such conditions of performance of the duties which provide the corresponding quality of care of the patient. The doctor is obliged to treat the patient kindly and with respect, to respect his personal dignity.. When treating persons suffering from mental illness, the doctor must be guided by the Law of Ukraine "On Psychiatric

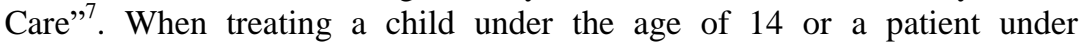
guardianship, the doctor is obliged to provide full information to his parents or guardians, obtain their consent to the use of a particular method of treatment or drug, and take into account the wishes of the patient. Exceptions may be cases of emergency life assistance. The doctor must protect the interests of the child or patient, who can not make their own decisions, if it is obvious that the interests of his life and health are indifferent to others or insufficiently aware of them.

The doctor must respect the honor and dignity of the patient, his right to privacy, treat him kindly, with understanding to perceive the concerns of relatives and friends of the patient. Every patient has the right to privacy. The doctor, as well as other persons involved in the provision of medical care, is obliged to maintain medical confidentiality even after the death of the patient, as well as the very fact of seeking medical care, unless the patient has ordered otherwise and his disease is not threatened. his loved ones and society. The secrecy applies to all information obtained during the treatment of the patient (including diagnosis, treatment methods, prognosis, etc.). Medical information about the patient may be disclosed: with the written consent of the patient; in case of a motivated request of the bodies of inquiry, investigation, prosecutor's office and court; if secrecy significantly endangers the health and life of the patient and (or) other persons (dangerous infectious diseases); in case of involvement in treatment of other specialists for whom this information is professionally necessary. Those persons, except the doctor, who have the right to access medical information, are obliged to keep confidential all information received about the patient, and must be informed by the doctor of the responsibility associated with its disclosure. Medical secrecy must be observed in the process of research, teaching students and improving doctors. Demonstration of the patient is possible only with his consent. for whom this information is professionally necessary. Those persons, except for the doctor, who have the right to access medical information, are obliged to keep confidential all information

7 Doctor's code of ethics. URL: https://zl.com.ua/ua/etic\%20codex/ (access date: 01.10.2020). 
received about the patient, and must be informed by the doctor about the responsibility associated with its disclosure. Medical secrecy must be observed in the process of research, teaching students and improving doctors. Demonstration of the patient is possible only with his consent. for whom this information is professionally necessary. Those persons, except for the doctor, who have the right to access medical information, are obliged to keep confidential all information received about the patient, and must be informed by the doctor about the responsibility associated with its disclosure. Medical secrecy must be observed in the process of research, teaching students and improving doctors. Demonstration of the patient is possible only with his consent.

The patient has the right to comprehensive information about his health, but he may refuse it or appoint a person to report his health. Information may be withheld from the patient in cases where there is good reason to believe that it may cause him serious harm. However, if the patient clearly states the requirement, the doctor must provide him with complete information. In case of an unfavorable prognosis for the patient it is necessary to inform him delicately and carefully, leaving hope for prolongation of life, for a possible successful result.

If a doctor makes a mistake or has unforeseen complications as a result of his actions, he is obliged to inform the patient, senior colleague or head of the unit, and in their absence, the administration of the institution where he works, and immediately take action to correct the harmful effects. waiting for instructions; if necessary, involve other specialists to honestly inform them about the essence of the error or complication that has arisen. The doctor should carry out the practice only under the own surname, without specifying unofficially appropriated, titles, degrees, ranks. The doctor is obliged to be as close to the dying patient as possible until the last moment of his life, to provide appropriate medical measures and supervision, to maintain a possible standard of living, to alleviate as much as possible physical and mental sufferings of the patient and his relatives by all available means. The doctor should promote the patient's right to receive spiritual support from a representative of the relevant religious denomination. The issue of termination of resuscitation should be decided, if possible collegially, in the case when a person's condition is defined as irreversible death in accordance with the criteria set by the Ministry of Health of Ukraine. The doctor has no right to knowingly hasten the onset of death and should not resort to euthanasia or involve others in its implementation. in the case when a person's condition is defined as irreversible death in accordance with the criteria defined by the Ministry of Health of Ukraine. The doctor has no right to knowingly hasten the onset of death and should not resort to euthanasia or involve others in its implementation. in the case when a 
person's condition is defined as irreversible death in accordance with the criteria defined by the Ministry of Health of Ukraine. The doctor has no right to knowingly hasten the onset of death and should not resort to euthanasia or involve others in its implementation.

The doctor has no right to leave his patients in cases of general danger.

The doctor may not offer the patient methods of treatment, drugs and medical devices that are not allowed for general use by the Ministry of Health of Ukraine in the manner prescribed by law.

Throughout his life, the doctor must: maintain respect and gratitude for the one who taught him the art of healing; to protect the honor and noble traditions of the medical community, to treat colleagues with respect and kindness, as well as other medical and support staff, constantly worrying about improving their skills. In severe clinical cases, physicians should provide advice and assistance to their colleagues in the correct form. For the treatment process, the full responsibility is borne only by the attending physician, who has the right to accept the recommendations of colleagues or to refuse them, guided solely by the interests of the patient. Physicians-heads of scientific and medical institutions are obliged to take care of the protection of moral and ethical positions and principles, personal dignity, as well as sufficient material security and social protection,

A doctor may not publicly question or discredit the professional qualifications of another doctor. Professional remarks addressed to a colleague must be substantiated, non-offensive in form, made in a personal conversation, before this issue is submitted for discussion to the medical community or the ethics committee (commission).

The doctor is obliged to constantly deepen and improve his knowledge and pass it on to his colleagues. Physicians must take an active part in the activities of medical societies. A doctor cannot use methods that are scientifically recognized as harmful or ineffective. He should also not cooperate with treatment providers without the appropriate qualifications. The medical staff should treat the medical staff with due respect and honor. But he should remember that only he has the right to decide on treatment. Physicians are united in supporting the actions of their self-governing body, whose task is to ensure that doctors have a proper position in society. If the good name of the doctor is tarnished and the relevant expert or medical court does not confirm the allegations, the victim has the right to apply to the medical self-government body to repair the damage caused to him. Regardless of where the doctor works: in a public, public or private institution, self-governing body, he must perform his duties in good faith in relation to these institutions. At the same time, a doctor should not follow the orders of employers if they contradict the principles of medical ethics and deontology or are harmful to human health. The doctor practices only 
under his own name. The doctor gains the reputation of a specialist based on the results of his own work. Any self-promotion is not desirable. The doctor must not consent to the use of his surname for commercial purposes. Alcohol celebrations are not allowed in medical facilities. The doctor has no right to impose his services on patients or to lure patients from other doctors. Before starting treatment, a private doctor has the right to determine the amount of his fee, except for emergency care. In the absence of appropriate prices, the doctor takes into account the cost of the service, own costs, their qualifications and, if possible, the property status of the patient. It is a good tradition to provide free and useless treatment to other health workers, their next of kin, as well as widows, widowers and orphans of health workers. If a doctor works in a medical institution that provides care to patients free of charge, he has no right to demand remuneration from them in any form. property status of the patient. A good tradition is the free and useless treatment of other health workers, their immediate relatives, as well as widows, widowers and orphans of health workers. If a doctor works in a medical institution that provides care to patients free of charge, he has no right to demand remuneration from them in any form. property status of the patient. It is a good tradition to provide free and useless treatment to other health workers, their next of kin, as well as widows, widowers and orphans of health workers. If a doctor works in a medical institution that provides care to patients free of charge, he has no right to demand remuneration from them in any form.

The principle of respect for one's profession must be maintained in all spheres of a doctor's activity: professional, public, journalistic, etc. Every physician should refrain from any action or statement that devalues respect for the medical profession. Throughout its activities, it should contribute to the preservation and enhancement of the prestige of the profession to which it belongs, as well as the effectiveness of this Code.

Thus, given its substantive provisions and social significance, the Code of Ethics of Physicians of Ukraine is a specific means of socio-psychological influence of public administration in the field of health care, which serves to improve the situation in this area.

\section{The impact of socio-psychological methods of public administration on the staff of domestic enterprises in the field of health care}

Over the last half century, the ability of the health care system to influence the health of the population has increased several times. Under its effective organization, according to WHO experts, the health care system can reduce overall mortality under the age of 75 - by $23 \%$ for men and $32 \%$ 
for women; and mortality from coronary heart disease - by $40-50 \%{ }^{8}$. In the XXI century. there was a change in the structure of mortality due to new trends and prospects for combating certain diseases. The deconstruction of the modern world, which is accompanied by changes in values and semantic orientations of human life in the XXI century, has also affected the quality of health of nations, which along with negative changes has led to negative consequences, including increased administrative and command methods and excessive bureaucratization. health care systems. The danger of such trends has trivially caused certain disparities between the real and hypothetically possible qualitative health indicators of the world's population, as a result of which disease prevention itself has become quite declarative, and public health management has become an affirmative tool. According to J. Wythworth, a change in the nature of the disease, contributed to a rapid change in lifestyle, which led to a violation of human adaptation in the environment, which tore man from his usual conditions, resulting in the formation of new diseases of civilization ${ }^{9}$. This indicates that the latest rhythms of social life have given rise to a new objective reality, within which man is in a situation of absolute vulnerability to adaptation requirements to it, and therefore, unable to adapt to the new reality, man faces modern diseases. Thus, the main cause of diseases of modern civilization is the inability of man to adapt to the conditions of the surrounding reality. It is mostly about a person's ability to organically have the immunity of medical and social adaptation to the conditions of objective reality and its functional ability to transform such reality in accordance with their own needs of individual life.

D. Staikler suggests taking into account the fact that the state of health of the population of modern Ukraine is characterized by a high prevalence of chronic diseases and socially dangerous diseases, resulting in high levels of disability and mortality in short life expectancy ${ }^{10}$. Indicators of health of the population of Ukraine over the last decade have had a negative trend, and now its condition is assessed as unsatisfactory, as evidenced by statistical indicators, in particular, the growth of tumors, circulatory system, respiratory system. In 2017, Ukraine ranked 118th out of 188 countries in terms of health and well-being of the nation. The Ukrainian average is 54 out

8 Center for Medical Statistics of the Ministry of Health of Ukraine. URL: http: // www.tat.gov.ua (appeal date: 01.10.2020).

${ }^{9}$ Implementation of medical reform is impossible without the development of primary infrastructure. URL: http://www.minregion.gov.ua/press/news/vprovadzhennyamedreformi-bezrozbudovi-infrastrukturi-pervinnoyi-lanki-nemozhlive-zubko/(appeal date: 01.10.2020).

${ }^{10}$ Stuckler D., Basu S., Suhrcke M., Coutts A., McKee M. Effects of the 2008 recession on health: a first look at European data. Lancet. 2011. July 9. № 378. R. 124-125. 
of 100 possible, along with Ukraine - Syria (117), Russia (119) and Belarus (120). The nearest European country - Moldova ranks 80th. The leaders of the ranking - Iceland, Singapore and Sweden - have 85 points each. The worst performers are in Africa, Central Asia and some Middle Eastern countries. According to this rating, the worst indicators in Ukraine are mortality from war (3), alcohol consumption (8), HIV infection (31), suicide (34) and violence (38). There are no threats to the health of the population in Ukraine only from such factors as natural disasters, malaria and forgotten tropical diseases, and therefore according to these indicators, Ukraine received 100 out of 100 possible points. Simultaneously.

The negative trend is even more evident in the case of data on coronary heart disease, where in Ukraine over the period under review mortality increased by more than $36 \%$, although in the group of "new" EU member states a similar trend was to reduce the average mortality rate. Thus, the medical and demographic situation in Ukraine remains difficult, which confirms the life expectancy of the population -68.2 years. This is on average 10 years lower than in EU countries. The premature mortality rate is three times higher than in these countries, including infant mortality 2.5 times; mortality from tuberculosis -20 times. The state of health of the population of Ukraine is unsatisfactory, as each citizen has almost two registered diseases. The deterioration of the health of the population and the decrease in its number in Ukraine are due to lower living standards, inflation, economic and political instability in society, as well as unsatisfactory activities of health care institutions. In other words, the poor health of the population is caused not only by a set of general socioeconomic problems, but also by a number of negative circumstances within the health care system ${ }^{11}$.

Since its independence, dissatisfaction with the functioning of Ukraine's health care sector has been observed not only among the population, but also among politicians and leaders. In this area, it was used primarily as a platform for political battles and lobbying the interests of certain progovernment or privileged groups. The low efficiency of the existing health care sector was affected by the frequent change of leadership of the relevant ministry, which was the political basis for revising the strategic directions of health care development. Reform programs, which replaced each other as soon as they began, led to public resistance and disbelief in the success of their implementation. Therefore, in general, such a situation could not radically and positively change the health care system and promote the introduction of alternative scientifically sound and less resource-intensive

\footnotetext{
${ }^{11}$ Mortality of the population of Ukraine in labor compensation. Weekly Demoscope. 2008. № 327-328. Pp. 13-15.
} 
methods to improve public health. However, such policies have limited the purchase of modern equipment for health care facilities and the introduction of innovative technologies in medical practice, reduced respect for health professionals and the quality of professional training of doctors, paramedics and increased their emigration to other countries ${ }^{12}$.

The situation of lack of specialists and hospitals is especially noticeable when comparing cities both within one region and between regions. Thus, if in the regional center or the capital most hospitals and clinics are renovated, have new equipment, then in ordinary cities, especially far from the center, there are often few clinics where people can get the necessary amount of medical services. Thus, the low efficiency of the health care system has a strong impact on the country as a whole, especially on its economy.

In the context of the organization of primary health care for the inhabitants of rural settlements at the regional level, there are risks for the effective implementation of health care reform and the achievement of certain results. Thus, in particular, the primary care physician should be interested in ensuring that people do not get sick. First, it reduces the burden on him: the healthier the population, the less the doctor's work. Secondly, the funding rate depends on the number and age of residents accompanied by a family doctor, ie those who have signed a declaration with him. For example, for the care of young children (0-5 years) the NHSU pays $z 1480$ per year, and for a person over the age of $65-z 740$. Again, there is a risk that doctors may resort to tricks and select young residents who rarely get sick. And even then, when the value of such a patient in terms of remuneration for his care is less than the value of pensioners and children, it also reduces the burden on him, in contrast to his colleague, who will remain elderly patients. Although the problem with signing the declaration in the village can be seen in all age groups. Due to global trends towards urbanization, the inability to find work and the desire for self-realization, young people leave villages and settlements en masse and move to live and work in the city. That is, the main clients of rural doctors will be the elderly. With such a workload, there will be no competition between doctors, which should be the driving force behind improving the quality of medical care. Although in some areas it is possible which will remain elderly patients. Although the problem with signing the declaration in the village can be seen in all age groups. Due to global trends towards urbanization, the inability to find work and the desire for self-realization, young people leave villages and settlements en masse and move to live and work in the city. That is, the main clients of rural doctors will be the elderly. With such a workload, no

${ }^{12}$ Karlash V.V. Mechanisms of state regulation in the field of public health of Ukraine: dis. : 25.00.02. Kharkiv, 2020. 214 p. 
competition between doctors, which should be the driving force behind improving the quality of health care, will take place ${ }^{13}$. Although in some areas it is possible which will remain elderly patients. Although the problem with signing the declaration in the village can be seen in all age groups. Due to global trends towards urbanization, the inability to find work and the desire for self-realization, young people leave villages and settlements en masse and move to live and work in the city. That is, the main clients of rural doctors will be the elderly. With such a workload, there will be no competition between doctors, which should be the driving force behind improving the quality of medical care. Although in some areas it is possible the inability to find work and the desire to self-realize young people leave villages and settlements en masse and move to live and work in the city. That is, the main clients of rural doctors will be the elderly. With such a workload, there will be no competition between doctors, which should be the driving force behind improving the quality of medical care. Although in some areas it is possible the inability to find work and the desire to selfrealize young people leave villages and settlements en masse and move to live and work in the city. That is, the main clients of rural doctors will be the elderly. With such a workload, there will be no competition between doctors, which should be the driving force behind improving the quality of medical care. Although in some areas it is possible ${ }^{14}$. Some services in the city can be provided by nurses. Instead, in rural areas, the patient, in particular an elderly person with a "bouquet" of chronic diseases, is in contact with the main person - a paramedic. But the law does not take this category of medical workers into account. A paramedic can now work only as part of a medical practice, and if there is no funding for a practice, there will be no paramedic. And with the available funding from the National Health Insurance Fund, the doctor will decide whether to share the money with the paramedic or not. An additional factor that may affect the quality of services provided to rural residents is the conditions in which doctors work and the functional state of health care facilities in rural settlements. Thus, according to the published information on the analysis of the situation with the provision of the rural population with doctors and the study of their working conditions in Ukraine, it became clear ${ }^{15}$.

The community-based / OTG health service is most in demand, and $80 \%$ of the OTG medical subvention, in the absence of appropriate primary care

\footnotetext{
${ }^{13}$ Karlash VV Mechanisms of state regulation in the field of public health of Ukraine: dis.: 25.00.02. Kharkiv, 2020. 214 p.

${ }^{14}$ Karlash V.V. Mechanisms of state regulation in the field of public health of Ukraine: dis..: 25.00.02. Kharkiv, 2020. 214 p.

${ }^{15}$ Rudy V.M. Legislative support for health care reform in Ukraine. Kyiv: Sfera, 2005. 272 p.
} 
management tools, is transferred to the district level. Communities do not yet have the leverage to control the quantity and quality of services provided. Primary care is one of the main functions delegated by the state to communities. Due to the medical subvention that the state transfers to the localities, communities must perform this service one hundred percent. Therefore, local governments are interested in ensuring that medical services are available and high quality. But the risk remains for communities that are unable to provide the population with quality health care, ie to guarantee access to primary health care for $100 \%$ of the population. Another problem remains unresolved: the regions can build everything, invite a doctor, and the doctor will have a small salary as a result of a medical subvention under the tariff grid, in case there is a delay in launching the NHS program. The legislative conflict, which is still unresolved, is the issue of choosing a doctor. There may be a situation where the community opens an outpatient clinic, invites a doctor to work, and most members of the community do not want to make a declaration with such a doctor. Given the medical reform, this is their right. Or a large number of people from another community will file a declaration with this doctor earlier, and the doctor has no right to deny the patient a declaration, until he has a contract with a certain number of patients. And so he is faced with the requirement to take patients from this community, although it is illegal. From the point of view of decentralization reform, this situation is considered a violation of community rights. If the head of the community spends money on infrastructure, provides additional opportunities and working conditions for the doctor, then it is completely unclear why the doctor earns money in the neighboring community without providing medical care where he is located. The doctor is under the dual authority of local authorities and the National Health Insurance Fund such a situation is considered a violation of community rights. If the head of the community spends money on infrastructure, provides additional opportunities and working conditions for the doctor, then it is completely unclear why the doctor earns money in the neighboring community without providing medical care where he is located. The doctor is under the dual authority of local authorities and the National Health Insurance Fund such a situation is considered a violation of community rights. If the head of the community spends money on infrastructure, provides additional opportunities and working conditions for the doctor, then it is completely unclear why the doctor earns money in the neighboring community without providing medical care where he is located. The doctor is under the dual authority of local authorities and the National Health Insurance Fund ${ }^{16}$.

${ }^{16}$ Karlash V.V. Mechanisms of state regulation in the field of public health of Ukraine: dis. 25.00.02. Kharkiv, 2020. 214 p. 
Marketing research shows that people do not trust both private and public medical institutions, because they are only sellers for them, and believe in the recommendations. In this case, the rule $3 / 11$ works very clearly - a satisfied customer will tell about it to only three of his acquaintances, and dissatisfied - to eleven. Business experts say that today's patients are well informed, so the doctor needs to learn to communicate a lot with his patient. The main thing is to hear the patient, to convey to him the care and his own arguments about the treatment. But, according to marketing research, the vast majority of doctors (almost 75\%) show a paternalistic style of behavior (pressure and directiveness), and only $15 \%$ are willing to interact. At the same time, only $15 \%$ of patients need paternalism, and $70 \%$ expect interaction ${ }^{17}$. Over the last ten years, various monitoring studies in Ukraine have found a relatively low level of public satisfaction with the quality of medical services, in particular, more than $60 \%$ of the population are convinced that the state is not able to objectively provide them with quality medical care. At the same time, about $76 \%$ of the population are wary of the introduction of appropriate innovations and reforms in the field of health care, and $31 \%$ are generally convinced that they will negatively affect the health of citizens. Therefore, within the deepening of certain crisis trends, the number of citizens in the country is objectively increasing, with a growing demand for quality medical care, and the health care system must be quite mobile, taking into account relevant technological innovations that have successful testing in today's world.

Involvement of personnel in the management of the quality of medical care and, as a result, the gradual abandonment of inspection control in favor of self-control is achieved by forming the necessary level of motivation in employees.

For doctors working in clinics, the main motivating factors are: the ability to help loved ones $-85.7 \%$, the need for people $-76.0 \%$, the benefit of people $-62.5 \%$, social status $-62.5 \%$, material benefits $-60.0 \%$, stable place of work $-55.6 \%$.

For doctors working in hospitals, the main motivating factors of work are: self-realization $-70.6 \%$, professional interest $-55.6 \%$, receiving material benefits $-45.0 \%$, a stable job $-44.4 \%$.

Doctors choose the following main incentives to improve the quality of medical care: material incentive $-72.5 \%$; respect for others and patients $52.1 \%$; moral satisfaction $-46.1 \%$; career opportunity $-28.1 \%$; professional growth $-18.0 \%$; leadership award $-6.0 \%$.

${ }^{17}$ Lekhan V.M., Slabkiy G.O., Shevchenko M.V. Health care development strategy: Ukrainian dimension. Kyiv, 2009. 34 p. 
The importance of the leadership award for physicians gradually decreases with increasing length of service (from $15.4 \%$ to $3.0 \%$ ). In addition, regardless of experience and place of work, doctors have one of the main motivating factors for moral satisfaction from work and respect for people. This confirms that in Ukrainian medicine, despite the low level of wages, the main priorities are the principles of humanism.

$44.9 \%$ of doctors do not satisfy the living conditions and material support of the workplace.

Among the respondents, $97.6 \%$ of doctors believe that it is necessary to introduce a system of motivation to provide quality medical services ${ }^{18}$.

Existing problems in the field of health care are factors that shape the professional trajectory of future doctors:

$-86.8 \%$ of respondents tend to build their future careers in the field of healthcare abroad, of which $15.1 \%$ - plan to go abroad immediately, and $71.1 \%$ - plan to start a career in Ukraine first, and already then leave;

- the most desirable for employment are: EU countries (67.3\%), USA and Canada (25.0\%), CIS countries (21.2\%), Australia (11.5\%);

$-100.0 \%$ consider abroad exclusively as a place of permanent residence and employment;

- for $83.0 \%$ of respondents it was their own choice, supported by parents / relatives / friends; $15.4 \%$ did not receive such support;

- the reasons for the propensity to work abroad are: higher wages $(87.2 \%$ of respondents); higher standard of living (78.7\%); higher level of medical development (70.2\%);

- degree of knowledge of a foreign (English) language: $17.6 \%$ of respondents allow them to maintain free professional and domestic communication; $23.5 \%$ - mediocre professional and free domestic communication; 58.9\% - mediocre professional and domestic communication;

$-35.4 \%$ of respondents are mentally ready to live abroad completely, $64.6 \%$ - only partially;

- $33.3 \%$ of respondents are fully ready to perform professional duties abroad, $66.7 \%$ - only partially;

- $89.6 \%$ of respondents agree to work exclusively as a doctor; $6.3 \%$ - allow temporary employment in the positions of junior / secondary medical staff;

${ }^{18}$ Melnichenko O.A., Udovichenko N.M. Controversy over the essence of the concept of "public administration of health care development". Innovations in the management of socio-economic development: materials and international. scientific-practical conf., March 5, 2018. Kharkiv: KHNUMG Publishing House, 2018. P. 258-260. 
- $23.4 \%$ of respondents tend to build their future careers abroad exclusively in the field of health care; $66.0 \%$ - allow a combination of a career in health care with work in other industries / areas; $10.6 \%$ - agree to any job, not at home;

- in order to achieve success, graduates of medical universities are willing to work hard: $20.8 \%$ - 40.0 hours; $37.5 \%$ - 40.1-60.0 hours; $20.8 \%-60.1-80.0$ hours; $20.8 \%$ - over 80 hours $^{19}$.

First of all, we should focus on the low level of efficiency of the entire health care system, which does not generate high quality medical services. The reasons for this state of affairs are the following:

- low level of responsibility of medical staff for the damage caused by the provision of poor quality medical care, which is due to the lack of an effective mechanism for responding to a case of incompetence of the doctor. The solution to this problem may be the introduction of a system of independent evaluation of doctors, which will involve the suspension or revocation of their license for poor quality services;

- low level of motivation of medical staff to provide quality medical services, as the official income of a doctor is not determined by the quality of his work from the patient's point of view. If you use the principle of "money follows the patient", the doctor will be motivated to provide quality medical care to anyone who applies ${ }^{20}$;

- lack of specialists, medical equipment, hospitals, which generate long queues of patients at the time of admission. Doctors have to work in an intensive mode, which automatically reduces the quality of services they provide;

- inability to receive the necessary medical care in a timely manner. This is a consequence of the lack of specialists, equipment, high prices of medicines and medical services;

- short schedule of patients. Often reception times end before $2 \mathrm{pm}$. Who did not have time to get to the reception, he is forced to come the next day, that is, to say goodbye to work again, therefore, not to perform a number of their duties. Such distraction of employees has a negative effect on the company itself (the degree of negative consequences will directly depend on the position of the employee and the possibility of his replacement), and on the employees of the company (reduction of wages);

${ }^{19}$ Melnychenko O., Litvinova K., Ryzhova D. Readiness of medical graduates for employment abroad. Public health in Ukraine: problems and ways to solve them: materials of III scientific practice. conf. with international uch., November 5, 2020. Kharkiv: KhNMU Publishing House, 2020. P. 96-97.

${ }^{20}$ Rudy V.M. Legislative support for health care reform in Ukraine. Kyiv: Sfera, 2005. 272 p. 
- low qualification of doctors. It is often the case that in two different clinics, doctors make different diagnoses for the same symptoms. Accordingly, the treatment does not give the expected effect;

- lack or aging of medical equipment. In most hospitals, examinations and treatment of patients are performed on Soviet equipment. And undergoing treatment or examination on new equipment (if any) currently costs a lot of money ${ }^{21}$;

- due to the introduction of an inefficient pay system in the work of the medical organization, employees are not focused on the end result of the activity, which leads to a decrease in the quality and satisfaction of patients with the provision of medical care. As a result of this process, health professionals do not participate in the discussion with their immediate superiors and the economic service of the medical organization of the provisions, criteria for assessing incentive surcharges and their size $\mathrm{e}^{22}$.

- lack of a proper culture of healthy living;

- lack of motivation of medical service providers to increase the efficiency and quality of their activities;

- a significant difference in the availability and quality of health care between the state, regional, oblast, rayon and rural levels of health care, as well as for rich and poor sections of the population;

- disproportions in the development of the medical services market;

- reducing the prestige of the profession of "doctor";

- weakness of public institutions of control over the health care system.

Thus, socio-psychological methods of public administration have a multi-vector impact on the staff of domestic enterprises in the field of health care, and therefore needs further improvement.

\section{CONCLUSIONS}

Research of current socio-psychological methods of public administration in the field of health care - a set of organizing, planning, coordinating and controlling techniques and methods of purposeful influence of the subject of management on the object of management taking into account the psychological laws of social cognition, interaction and relationships between them, aimed at implementing public administration tasks - revealed the specifics of their influence in this sphere. Depending on

${ }^{21}$ Ukrainian Institute for Strategic Studies of the Ministry of Health of Ukraine. URL: http: //www.uiph.kiev.ua/index.asp?p=information\&s=2. (appeal date: 01.10.2020).

${ }^{22}$ Melnichenko O.A., Kosilova O.Y., Kravchenko Zh.D., Makarova V.I. Problems of development of the domestic sphere of health care as a factor of deterioration of quality of life of the population of Ukraine: public-administrative dimension. Development strategy of Ukraine: financial, economic and humanitarian aspects: materials of the VII International. scientific-practical Conf., October 16, 2020. Kyiv: IAA, 2020. P. 369-371. 
the specific situation, public administration entities (public administration bodies, local self-government bodies, representatives of business and the population) use (partly simultaneously) appropriate means of sociopsychological methods of public administration in the field of health care.

\section{SUMMARY}

In this article we investigated current practical methods of public administration in the field of health care. Depending on the specific situation, public administration entities (public administration bodies, local self-government bodies, representatives of business and the population) use (partly simultaneously) appropriate means of socio-psychological methods of public administration in the field of health care.

\section{REFERENCES}

1. Code of Ethics of the Doctor of Ukraine. Transport medicine of Ukraine. 2009. № 4. S. 6-11.

2. Doctor's code of ethics. URL: https://zl.com.ua/ua/etic\%20codex/ (access date: 01.10.2020).

3. On the implementation of the Code of Ethics for Physicians. Order of the Main Department of Health of the Lviv Regional State Administration dated December 13, 2007 № 861. URL: http://ult.lviv.ua/?page_id=56 (access date: 01.10.2020).

4. Health systems, health and well-being: an assessment of the arguments in favor of investing in health systems. WHO, 2008. S. 125-132.

5. Center for Medical Statistics of the Ministry of Health of Ukraine. URL:http: // www.tat.gov.ua (appeal date: 01.10.2020).

6. Implementation of medical reform is impossible without the development of primary infrastructure. URL: http://www.minregion.gov.ua/ press/news/vprovadzhennya-medreformi-bezrozbudovi-infrastrukturipervinnoyi-lanki-nemozhlive-zubko/. (appeal date: 01.10.2020).

7. Stuckler D., Basu S., Suhrcke M., Coutts A., McKee M. Effects of the 2008 recession on health: a first look at European data. Lancet. 2011. July 9. № 378. R. 124-125.

8. Medyanyk GEFormation of mechanisms of state regulation in the system of financing of health care institutions of communal form of ownership: author's ref. dis. 25.00.02. Zaporozhye, 2010. 23 p.

9. Mortality of the population of Ukraine in labor compensation. Weekly Demoscope. 2008. № 327-328. Pp. 13-15.

10. Karlash V.V. Mechanisms of state regulation in the field of public health of Ukraine: dis. 25.00.02. Kharkiv, 2020. 214 p.

11. Lekhan V.M., Slabkiy G.O., Shevchenko M.V. Health care development strategy: Ukrainian dimension. Kyiv, 2009. 34 p. 
12. Melnichenko O.A., Udovichenko N.M. Controversy over the essence of the concept of "public administration of health care development". Innovations in the management of socio-economic development: materials and international. scientific-practical conf., March 5, 2018. Kharkiv: KHNUMG Publishing House, 2018. P. 258-260.

13. Melnychenko O., Litvinova K., Ryzhova D. Readiness of medical graduates for employment abroad. Public health in Ukraine: problems and ways to solve them: materials of III scientific practice. conf. with international uch., November 5, 2020. Kharkiv: KhNMU Publishing House, 2020. P. 96-97.

14. Rudy V.M. Legislative support for health care reform in Ukraine. Kyiv: Sfera, 2005. 272 p.

15. Ukrainian Institute for Strategic Studies of the Ministry of Health of Ukraine. URL: http: //www.uiph.kiev.ua/index.asp?p=information\&s=2. (appeal date: 01.10.2020).

16. Melnichenko O.A., Kosilova O.Y., Kravchenko Zh.D., Makarova V.I. Problems of development of the domestic sphere of health care as a factor of deterioration of quality of life of the population of Ukraine: public-administrative dimension. Development strategy of Ukraine: financial, economic and humanitarian aspects: materials of the VII International. scientific-practical Conf., October 16, 2020. Kyiv: IAA, 2020. P. 369-371.

Information about the authors: Chovpan G. O.,

Candidate of Physical and Mathematical Sciences, Associate Professor at the Department of Medical and Biological Physics and Medical Information Science Kharkiv National Medical University 4, Nauky avenue, Kharkiv, 61000, Ukraine

Batyuk L. V., Candidate of Biological Science, Associates of Professor at Department of Biological and Medical Physics and Medical Information Science Kharkiv National Medical University 4, Nauky avenue, Kharkiv, 61000, Ukraine 